\title{
Effects of Country Personality on Foreign General Product Attitude Through Self- Congruity and General Product Country Images in an Emerging Country: An Abstract
}

\author{
Paul Chao, Murat Aktan, and Lei Zhang
}

\begin{abstract}
This research is designed to test the robustness of the country personality (CP) construct in an emerging country - China. It further examines the effects of $\mathrm{CP}$ on consumer general product attitude (GPA) through the consumer's self-congruity and the general country image (GCI) using the structural equation modeling approach. We ask a sample of consumers in China to evaluate four countries: USA, Japan, China, and Turkey.

The results reveal both the direct effect of $\mathrm{CP}$ on GPA and indirect effects through self-congruity and GCI with GCI showing the greatest impact followed by the CP's rigorous dimension and self-congruity as the mediator. These results suggest significant managerial implications for international marketers. They should focus on building or promoting a more positive GCI either by improving the product or service quality of the country products or the country image as a whole, which can then be leveraged to generate a better GPA. Since self-congruity serves as an effective mediator between $\mathrm{CP}$ and GPA, international marketers can focus on promoting a country image to bring $\mathrm{CP}$ closer to the self-concept of the consumers in an emerging market. This can in turn affect the GPA indirectly.
\end{abstract}

\footnotetext{
P. Chao $(\triangle)$

Eastern Michigan University, Ypsilanti, MI, USA

e-mail:paul.chao@emich.edu

M. Aktan

Nevsehir Haci Bektas Veli University, Nevşehir, Turkey

e-mail: murat.aktan@nevsehir.edu.tr

L. Zhang

University of Electronic Science and Technology, Chengdu, China

e-mail: mouclim@yahoo.com
} 